* Advogada, mestra em Direito Negocial pela Universidade Estadual de Londrina (UEL), especialista em Direito e Processo do Trabalho. E-mail: deborahdemeira@gmail.com

\footnotetext{
** Mestre e doutor em Direito do Estado/Direito Constitucional pela PUC/SP, professor do curso de mestrado em Direito Negocial da Universidade Estadual de Londrina (UEL).E-mail: marcosstriquer@uol.com.br
}

\section{O BNDES NaS Visões de Liberalismo E do Republicanismo Neorromano de Philip Pettit}

\author{
BNDES FROM THE LIBERALISM AND THE NEORROMAN \\ Republicanism of Philip Pettit Perspective
}

\section{Déborah de Meira Málaque* Marcos Antonio Striquer Soares**}

Como citar: MALAQUE, Déborah de Meira; STRIQUER SOARES, Marcos Antônio. O BNDES nas visões de liberalismo e do republicanismo neorromano de Philip Pettit. Revista do Direito Público, Londrina, v. 15, n. 1, p. 26-45, abr. 2020. DOI: $10.5433 / 24157-108104-1.2020 v 15 n 1$ p. 26 . ISSN: $1980-511 \mathrm{X}$

Resumo: Esta pesquisa pretendeu analisar o comportamento do Banco Nacional de Desenvolvimento Econômico e Social, a partir de duas concepções doutrinárias que se destacam: o liberalismo e o republicanismo. Tais correntes de pensamento apresentam abordagens distintas no que tange ao conceito de liberdade, e suas apresentações trazem contribuições importantes para o estudo daquele Banco Público. Especialmente no que se refere ao republicanismo, o chamado republicanismo neorromano será objeto de maior estudo, especialmente o desenvolvimento doutrinário de Philip Pettit e suas premissas para a construção de uma democracia contestatória. Para tanto, optou-se pela utilização do método de abordagem dedutivo, onde por meio dos conceitos gerais, serão feitas aplicações concretas no comportamento do BNDES. Alguns pontos se destacaram na conclusão da pesquisa: a) verificou-se a ausência de um planejamento estatal voltado ao desenvolvimento nacional, b) carência de ações transparentes e de publicidade nos motivos que culminaram com a concessão de investimentos e empréstimos; c) estão presentes alguns fatores que revelam a presença de arbitrariedades e de dominação estatal para com o cidadão, tornando-se imprescindível a mudança no direcionamento da conduta do Banco Público para que o particular tenha condições de contestar as ações que divergem do interesse público.

Palavras-chave: BNDES. Liberalismo. Republicanismo. Philip Pettit. Interesse Público. 
Abstract: This research analyzes the behavior of the National Bank for Economic and Social Development (BNDES), based on two doctrinal conceptions: liberalism and republicanism. These schools of thought represent different approaches of the concept of freedom. As a result, the understanding of this subject-matter can help in promoting new ideas in the realm of the BNDES. Furthermore, neo-Roman republicanism will also be analyzed, especially the works of Philip Pettit and his premises for the construction of a contested democracy. In order to analyze this subject, this paper used the deductive method, where, with use of general concepts, concrete explanations are made in regards to the behavior of BNDES. Some points were highlighted in the conclusion of this research: a) there was a lack of state planning aimed at national development, b) there was a lack of transparent actions and publicity for the reasons that led to the granting of investments and loans; c) some factors reveal the presence of arbitrariness and state domination towards the citizen, making it essential to change the direction of the Public Bank actions, so that the individual may choose to contest actions that diverge from the public interest.

Keywords: BNDES. Liberalism. Republicanism. Philip Pettit. Public interest. 


\section{INTRODUÇÃO}

A problemática do presente artigo e a construção de suas premissas foram desenvolvidas durante o Programa de Mestrado de Direito Negocial da UEL-PR, no período de agosto de 2016 a fevereiro de 2018. Os estudos culminaram com a apresentação da dissertação elaborada pela primeira autora, sob a orientação do segundo autor, com o seguinte título: "Um estudo sobre o BNDES a partir das concepções liberais e republicanas de liberdade: contribuições para formação de uma democracia contestatória delineada por Philip Pettit".

Os estudos revelaram que desde a sua constituição, as ações do Banco Nacional do Desenvolvimento Econômico e Social (BNDES) trilharam diferentes ideologias e que traduziram maior ou menor espaço de liberdade dos indivíduos no acompanhamento das decisões daquele Banco. Portanto, o debate abrangeu o estudo do BNDES a partir dos apontamentos doutrinários das doutrinas que mais se destacam no estudo da liberdade: o liberalismo e o republicanismo.

Nesse viés, o primeiro tópico tratará sobre o conceito de liberdade para os liberais e para os republicanos, com uma reflexão sobre as variações da liberdade dos antigos e modernos, aliada à noção de liberdade positiva e negativa. Serão expostas as construções históricas e os principais expoentes de cada vertente.

Já no segundo tópico, têm-se as delineações trazidas por Philip Pettit e o chamado republicanismo neorromano. O referido doutrinador aponta aquelas características que não permite que o cidadão seja dominado pelo poder estatal, e assim, não haja arbitrariedades. Assim, a formação de uma democracia contestatória requer ações transparentes e voltadas para o interesse público, aliadas a possibilidades de contestação pelo particular.

Por fim, o último tópico tratará sobre os objetivos que estão envoltos no conceito de desenvolvimento nacional, e principalmente na indispensabilidade do planejamento estatal para um bom desempenho das atividades estatais, no sentido de evitar o uso dessa instituição do Estado para a dominação da sociedade. Ademais, será feito um exame do comportamento do BNDES e as principais diretrizes do liberalismo e do republicanismo, especialmente do republicanismo neorromano. Neste ponto, uma investigação sobre as principais atualidades que permeiam o BNDES serão objeto de estudo, partindo-se das premissas que foram lançadas durante toda a pesquisa.

A metodologia aplicada nesta pesquisa será a bibliográfica, com a observação de relevantes construções doutrinárias e o confronto com os aspectos práticos nas ações do BNDES.

\section{A LIBERDADE PARA OS LIBERAIS E PARA OS REPUBLICANOS}

No decorrer dos anos, o diagnóstico sobre o conceito de liberdade, seus limites e componentes, esteve presente em grandes estudos filosóficos e doutrinários. Os conflitos intelectuais almejavam justificar e estruturar o poder político através do estudo da liberdade, além de tratar sobre os limites das ações humanas. 
Entretanto, tais concepções se modificaram juntamente com as transformações políticas, sociais e econômicas. Veja-se primeiramente na Idade Antiga, onde a ideia de liberdade não estava associada a uma forma individual ou ainda em um aspecto subjetivo, mas sim para a coletividade e a integração do indivíduo ao corpo social. Celso Lafer (1980, p. 17) preleciona que, "a liberdade antiga é a liberdade do cidadão e não a do homem enquanto homem. Ela só se manifesta, por isso mesmo, em comunidades políticas que regularam adequadamente a interação da pluralidade".

Neste mesmo sentido, Miguel Reale (2002, p. 628) destaca o predomínio da concepção política nas sociedades romanas e gregas, apontando ainda que, a cidadania predominava na vida do particular, e o valor deste indivíduo permanecia somente enquanto houvesse o "elo de uma vivência coletiva, integrado na civitas" (REALE, 2002, p. 628).

Já na Idade Média (séculos V ao XV), a liberdade dos indivíduos estava inicialmente condicionada aos interesses e vontades da Igreja, e mais tarde, com a ascensão das monarquias nacionais e a perda do poder político dos papados, o Estado desponta como o concretizador e condutor da liberdade. Thomas Hobbes (1588-1679) em sua obra "Leviatã" preleciona que não há liberdade sem o Estado, afirmando ainda que o Estado é resultado da multidão reunida numa só pessoa, tem poder e força para assegurar a paz e a defesa comum (HOBBES, 2009, p. 126-127).

A progressão destes pensamentos, e o surgimento de uma visão mais subjetiva do conceito de liberdade não foram instantâneos e pacíficos. Grandes paradigmas inerentes à própria estrutura da sociedade foram rompidos de forma gradual, a partir da inclusão de pensamentos mais inclusivos e igualitários dos indivíduos. A Revolução Francesa (1789) suscita a ideia de uma liberdade que deve coexistir com outras liberdades, abrindo espaço para novas doutrinas e pensamentos.

Nesse contexto, desponta a doutrina do liberalismo, como uma das mais importantes correntes de pensamento da história, e que desenvolveu um conceito de liberdade desde o indivíduo considerado em si mesmo, e não apenas como parte de um corpo social.

Destarte, em 1819, Benjamim Constant, um romancista, filósofo da religião e pensador político, descreve sobre as concepções de liberdade dos antigos e dos modernos. Para este escritor, o objetivo dos antigos era a divisão do poder social entre todos os indivíduos de uma pátria comum, por meio de uma participação ativa da coletividade (CONSTANT, 1985, p. 15). Já os modernos têm por meta, "a segurança dos privilégios privados; e eles chamam liberdade as garantias concedidas pelas instituições a esses privilégios" (CONSTANT, 1985, p. 16).

A interpretação de Benjamin Constant traz a ideia de um sentimento individualista que se formou nos tempos modernos, restando demonstrado que a preocupação da civilização moderna é distinta daquelas anteriores que tinham a participação pública como anseio primordial. Neste ponto, os indivíduos buscavam independência em suas vidas privadas, e as instituições seriam mecanismos para assegurar que a liberdade daqueles seria mantida e não sofreria interferência.

Estes parâmetros elaborados por Benjamin Constant foram utilizados pelo filósofo europeu Isaiah Berlin para o debate político sobre a liberdade e suas diferentes acepções, especialmente sobre os modelos positivos e negativos de liberdade. Isaiah Berlin aponta para o fato que no mundo antigo, não havia uma discussão sobre a liberdade individual como um ideal político consciente 
Para a acepção positiva de liberdade, tem-se a resposta da pergunta "O que ou quem é a fonte de controle ou interferência capaz de determinar que alguém faça ou seja uma coisa em vez de outra?" (BERLIN, 2002, p. 229). No caso do sentido negativo de liberdade, o questionamento é "Qual é a área em que o sujeito - uma pessoa ou grupo de pessoas - é ou deve ter permissão de fazer ou ser o que é capaz de fazer ou ser, sem a interferência de outras pessoas?" (BERLIN, 2002, p. 229).

A partir desta perspectiva, a concepção dada pelo liberalismo à liberdade, integra uma concepção negativa, isto é, a liberdade do homem entendida a partir da ausência de interferência de outro homem ou de outro grupo nas suas atividades (BERLIN, 2002, p. 229).

Ademais, o liberalismo apresenta a liberdade individual e a autonomia como aspectos e valores fundamentais, integrando os limites definidos pela lei, para que o indivíduo tenha um campo de ação mais amplo possível, não sendo impedido, obstruído ou coagido por ninguém (RAMOS, 2005, p. 236). O Estado liberal tem assim como característica a neutralidade, de forma que suas ações devem ser imparciais para possibilitar que os indivíduos exerçam suas opções de escolhas sem impedimento estatal.

Entrementes, a doutrina liberal não evidenciava o valor cívico do homem, desprezando-o em detrimento de formas privadas de existência social e econômicas, havendo a substituição do homo politicus pelo homo economicus e socialis (RAMOS, 2007, p. 302). Viu-se assim a necessidade do renascer de uma doutrina política e filosófica que foi de extrema importância para construção e consolidação das sociedades antigas: o republicanismo.

Dentre as vertentes desse republicanismo, destaca-se a corrente denominada neorromana. Neste caso, diferente da corrente liberal que aborda a liberdade negativa como a ausência de interferência, os neorromanos sustentam que, mesmo com a não interferência, a liberdade pode ser suprimida se presente a dominação. Estes estudos foram substancialmente aprofundados pelo doutrinador Philip Pettit, que trouxe sua ótica sobre a liberdade e a formação de uma democracia contestatória.

\section{PHILIP PETTIT E O REPUBLICANISMO NEORROMANO}

Em primeiro plano, cumpre destacar que Philip Pettit refuta uma ideia preconcebida que a tradição republicana seja vinculada a uma vertente populista ou comunitarista (PETTIT, 1999, p. 25). Este doutrinador entende que o ideal comunitário presente na liberdade republicana é compatível com as modernas e pluralistas sociedades atuais, contudo a participação democrática não é tida como um valor básico e indispensável, mas como um mecanismo para que seja possível desfrutar da liberdade como não dominação (PETTIT, 1999, p. 25).

Destarte, Philip Pettit propõe uma releitura do conceito de liberdade negativa, indo além da ideia de não interferência, propondo a liberdade como não dominação. Tal liberdade será plenamente desfrutada apenas se houver possibilidade de escolha sem a sujeição a um poder arbitrário de interferência vindo de um poder estatal ou de outra pessoa. O ponto de análise é a 
dominação ou não da escolha, sem barreiras ao tipo ou à quantidade de escolhas.

Para o autor "a liberdade deve ser definida como uma situação que evita os males ligados à interferência, não como o acesso a instrumentos de controle democráticos, participativos ou representativos" (PETTIT, 1999, p. 50, tradução livre). O controle democrático é importante, mas não é suficiente. Pettit desacredita, com isso, tanto a liberdade dos antigos como a liberdade positiva como critério predominante de caracterização da liberdade.

A não interferência (a liberdade negativa, a liberdade do liberalismo) não é suficiente, é preciso alcançar a não-dominação:

A tradição republicana é unânime ao apresentar a liberdade como o oposto da escravidão, como é ao ver a exposição à vontade arbitrária de outro - ou viver à mercê de outro - como o grande mal. [...] O contraste entre liberdade e escravidão revela claramente que a liberdade é tomada no sentido de não-dominação, e não de não-interferência (PETTIT, 1999, p. 52, tradução livre).

Em outra passagem o autor ainda esclarece: “A condição de liberdade é ilustrada pelo status de alguém que, ao contrário do escravo, não está sujeito ao poder arbitrário do outro, isto é, de alguém que não é dominado pelo poder arbitrário de qualquer outro" (PETTIT, 1999, p. 51-52). Conforme Cesar Ramos (RAMOS, 2007, p. 310):

A condição do escravo caracteriza-se pelo domínio que o senhor exerce sobre ele. Quando o primeiro torna-se permissivo e tolerante, mesmo assim, continua o estado de dominação sem, entretanto, haver uma efetiva e real interferência do senhor. Por mais que o escravo goze de liberdade negativa (ausência de interferência), ainda assim não se liberta da sua condição de servidão, continuando a pertencer ao seu senhor.

Quentin Skinner (1999, p. 40) investigou o republicanismo neorromano a partir de autores do Séc. XVII e esclarece que a perda da liberdade do corpo político deve ter o mesmo significado da perda da liberdade para a pessoa individual e que sofrer a perda da liberdade individual significa ser transformado em escravo. Mais adiante (SKINNER, 1999, p. 43-44), explica que "a essência do que significa ser um escravo, e portanto a falta de liberdade pessoal, é assim estar in potestate, dentro do poder de alguém mais"; à esta condição (estar in potestare de alguém) é acrescentada outra, para caracterizar a escravidão, a "condição na qual alguém é obnoxius, perpetuamente sujeito ou propenso a maus-tratos ou punição"; o termo obnoxius é utilizado para descrever o predicamento de qualquer um que dependa da vontade de alguém mais. Ser livre, portanto, é estar na condição inversa à de escravo, é não estar sob o poder de outro e não depender da vontade de outro.

Analisando a história romana a partir de Lívio, Quentin Skinner (1999, p. 45-46) explica que um Estado livre "é um Estado em que há magistraturas eleitas anualmente e uma sujeição igual de todo cidadão ao domínio da lei”. Citando os autores neorromanos do Séc. XVII, o autor 
(SKINNER, 1999, p. 47) explica que o corpo político será desprovido de liberdade, caindo na servidão pública, "se for forçosa ou coercivamente privado de sua capacidade de agir à vontade na busca de fins que escolheu". Mais adiante ele explica que a servidão pública pode emergir "quando a constituição interna de um Estado permite o exercício de quaisquer poderes discricionários ou privilegiados da parte daqueles que o governam" (SKINNER, 1999, p. 50).

Percebe-se dessas notas, que a orientação do republicanismo neorromano, além da não dominação, também põe sua ênfase na observância da lei e na persecução de fins, objetivos escolhidos pela própria comunidade. Por outro lado, as autoridades podem levar a comunidade a uma servidão pública em razão do uso de seus poderes discricionários ou privilegiados. Dito de outro modo, a república exige a persecução de fins que satisfaçam os interesses de toda a comunidade e não os interesses de um ou de um grupo de privilegiados no desempenho do governo. O que se constata é que pode existir a dominação de toda uma comunidade, no mundo contemporâneo, quando o corpo dos governantes, especialmente o Legislativo e o Executivo, traçam políticas públicas e conduzem os atos de governo conforme fins particulares (de interesse pessoal ou do grupo que se encontra no poder) e não fins de interesse da sociedade.

Neste viés, exige-se um Estado constitucional forte, onde as instituições garantam e formem a liberdade, de maneira que não se verificará arbitrariedade estatal quando este ente trilhar os interesses comuns assumidos pelos cidadãos (PETTIT, 2007, p. 213). Estas metas são alcançadas por meio de um regime eleitoral democrático, pelo império das leis, pela separação dos poderes, e por uma realidade cívica reconhecida com base em razões objetivas (PINTO, 2001, p. 471).

César Augusto Ramos (2007, p. 312) preleciona que há um duplo aspecto na liberdade republicana: a ausência de interferência e na ausência de dominação, onde estes dois requisitos se ajustam de forma solidária. Para tanto, evita-se o formalismo jurídico presente na simples ausência de impedimentos externos, e esquiva-se do mero autogoverno da liberdade positiva (RAMOS, 2007, p. 312).

Philip Pettit afirma ainda que são necessárias três condições para que o regime constitucional possa garantir a liberdade e não ser manipulado: 1) o sistema constitucional deve constituir um "império de leis e não de homens", conforme prelecionado por James Harrington; 2) os poderes legais devem ser distribuídos entre diferentes partidos; 3) as leis devem ser relativamente resistentes à vontade da maioria (PETTIT, 1999, p. 227-228).

Entretanto, a operacionalização do regime constitucional não é suficiente para garantir que os cidadãos desfrutem da liberdade almejada. Não se pode constituir um arcabouço normativo tão minucioso que elimine certa a discricionariedade nas decisões dos governantes, o que sequer seria desejável em um Estado republicano (SILVA, 2011, p. 39-40). Permanecerá a possibilidade de atuação e decisão de grupos, instituições e outros entes de poder conforme a discricionariedade que lhe parecer mais adequada.

Nesse sentido, Philip Pettit aduz que à constitucionalidade do Estado republicano devese aliar a democracia contestatória, consubstanciada em "um conjunto de práticas e mecanismos institucionais que aponta para a reconciliação da liberdade negativa das pessoas particulares com 
a participação efetiva do povo nos assuntos públicos." (SILVA, 2011, p. 41).

Neste modelo, há uma conjugação de elementos democráticos que sejam capazes de refutar a corrupção dos governantes e que atuem além de uma simples democracia eleitoral: "a ideia é que instituições democráticas devidamente concebidas deveriam dar aos cidadãos não somente direitos eleitorais mas também oportunidades efetivas para contestar as decisões de seus representantes"1 (LOVETT; PETTIT, 2009, p. 15, tradução livre).

Contudo, nesta proposta de democracia contestatória não se observa uma forma democrática populista que exige participação direta dos cidadãos nas deliberações, mas é suficiente que haja uma vigilância sobre o funcionamento das leis, dos governantes e das instituições (MEDINA, 2007, p. 128). Diante da complexidade da sociedade moderna, esta participação política torna-se mais atrativa para os cidadãos sem oportunidade de atuar diretamente na vida pública.

Enuncia Philip Pettit que,

[...] um estado será não-arbitrário na proporção em que ele é forçado a trilhar os interesses comuns assumidos pelos cidadãos e somente os interesses comuns assumidos pelos cidadãos. Argumento que a melhor esperança para forçar o Estado a trilhar tais interesses, é ter um regime eleitoral democrático, e o que força o Estado a trilhar somente tais interesses é admitir um regime que descrevo como democracia contestatória (PETTIT, 2007, p. 213).

Contemple-se que a vertente eleitoral em uma democracia tem extremo destaque, já que permite que os cidadãos avaliem os posicionamentos e ideias daqueles que se submeteram ao processo e pretendem representar os ideais do povo, revelando o controle popular dos cidadãos na escolha de seus representantes, e o impedimento do poder indefinido e perpétuo.

Entrementes, a democracia contestatória ultrapassa os ditames eleitorais e abarca um envolvimento dos indivíduos nas questões públicas a partir de espaços abertos para contestação das decisões do governo e concretização do bem comum.

De um âmbito metódico, Frank Lovett e Philip Pettit (2009, p. 15) descrevem que para a materialização da democracia contestatória, são necessários no mínimo três marcas: 1) existência procedimentos formais explícitos, de conhecimento geral, pelo qual as instituições governamentais exercem sua autoridade; 2) aqueles que exercem o poder devem ser compelidos a apontar os motivos para suas resoluções, e esses motivos devem estar sujeitos a público debate; 3 ) existência de fóruns institucionalizados para que os particulares contestem, levantem objeções às leis e às políticas públicas, e, tenham respostas às suas indagações.

Ora,

Para fomentar a liberdade enquanto não-dominação é necessário que as decisões públicas tenham como base a perscrutação dos interesses e idéias dos cidadãos afetados. A tomada de decisão deve exibir uma forma tal que todos possam

1 Original: "The Idea is that properly designed democratic institutions should give citizens not only electoral rights but also the effective opportunity to contest the decisions of their representatives". 
aprová-la e com ela se identificar. Tanto as decisões do legislativo como as do executivo e as do judiciário devem trazer a marca dos anseios e modos de pensar dos cidadãos (ELIAS, 2008, p. 49).

Em resumo, um Estado republicano contestatório, dedica-se à inclusão e às respostas para as demandas públicas, municiando o cidadão com todos os meios hábeis para que este refute as decisões governamentais.

A partir destes apontamentos de Philip Pettit sobre a democracia contestatória, objetiva-se examinar os caminhos percorridos pelo BNDES, Banco Nacional do Desenvolvimento Econômico e Social, como uma das mais destacadas instituições públicas brasileiras.

As formulações deste doutrinador para instituir a liberdade como não dominação, podem ser utilizadas de subsídios para o acompanhamento institucional do BNDES, e, consequentemente, observar as alternativas existentes para que este banco público não atue através de interferências arbitrárias.

\section{O DESENVOLVIMENTO NACIONAL A PARTIR DO BNDES E A DEMOCRACIA CONTESTATÓRIA}

O estudo do desenvolvimento nacional se revela indispensável para a compreensão dos elementos e das ações do BNDES, vez que sua principal meta é o suporte de obras e serviços que promovam o desenvolvimento econômico e social.

Gilberto Bercovici (2005, p. 51) aponta que o desenvolvimento é condição indisponível para a realização do bem-estar social, sendo o Estado, por meio do planejamento, o principal promotor do desenvolvimento. O referido autor ainda descreve que a ideia de planejamento está baseada na "perseguição de fins que alterem a situação econômica e social vivida naquele momento. É uma atuação do Estado voltada essencialmente para o futuro.” (BERCOVICI, 2003, p. 192). Destaca-se, daí, uma orientação republicana no planejamento do desenvolvimento. Não basta criar políticas públicas e satisfazer as necessidades de alguém do povo. Se o planejamento se dispõe a perseguir fins, com ações voltadas para o futuro, deve ter caráter republicano, voltado para satisfação de interesse de toda a comunidade e não de interesses de um ou de um grupo.

Neste ínterim, o Estado para destacar o desenvolvimento em seu território, deve elaborar metas possíveis e necessárias, coordenando esforços através de um planejamento prévio. Por conseguinte, a noção de planejamento está necessariamente ligada à ideia de desenvolvimento.

Nos termos do artigo 174 da Constituição Federal (BRASIL, 1988), e seu parágrafo primeiro, tem-se a indispensabilidade do planejamento estatal, especialmente no que tange às atividades econômicas. Destarte, pode-se observar que o planejamento efetuado pelo Estado para as ações do BNDES, ou ainda, a falta de planejamento estruturado para suas atuações, demonstra o seu comprometimento ou a ausência dele para com os valores adotados na Carta da República.

Procedimentos alinhados e justificados com o interesse público devem permear o 
planejamento das condutas do BNDES enquanto instrumento de políticas de investimento. Estas premissas se justificam vez que o planejamento é o mecanismo estatal para direcionamento do desenvolvimento nacional.

Dentro deste contexto, José Francisco Cunha Ferraz Filho (2012, p. 8) aponta que desenvolvimento nacional é o progresso econômico, político, social e cultural da nação, já que o progresso nestas áreas gera a ampliação do bem-estar dos povos, com riqueza e melhoria das condições sociais.

Entrementes, a ideologia presente no desenvolvimento nacional não está limitada à definição de desenvolvimento econômico. O primeiro se revela mais inclusivo, abarcando uma perspectiva econômica, e também uma visão de desenvolvimento social, político, cultural e quaisquer outros valores nacionais expressos pelo legislador constituinte.

O desenvolvimento nacional integra assim, o aperfeiçoamento do indivíduo além do fortalecimento das instituições. Ademais, exige a retirada das principais fontes de privação de liberdade: a pobreza, a tirania, falta de oportunidades sociais, negligencia dos serviços públicos (SEN, 2000, p. 18).

Não se pode olvidar que a programação do desenvolvimento quando concebida no plano econômico ou no político, acarreta como efeito o desenvolvimento social, “e, portanto, maior homogeneidade no regime de participação com a consequente transformação do regime políticosocial da comunidade" (JAGUARIBE, 2013, p. 397).

Por fim, pondera-se que, foi iniciado nas últimas décadas, uma mudança de pensamento sobre as ações governamentais e a intervenção do Estado para uma melhor distribuição de renda e promoção do desenvolvimento. Entretanto, é indispensável a conjugação de esforços mais incisivos das instituições públicas, que agreguem resultados mais práticos para a população.

\subsection{O Bndes a Partir Das Visões do Liberalismo e do Republicanismo}

Como visto acima, o BNDES tem como premissa a promoção do desenvolvimento econômico e social. Contudo, em sua constituição original, denominada de BNDE (Banco Nacional do Desenvolvimento Econômico), seus objetivos incluíam somente o desenvolvimento econômico, tal como preconizado na Lei n. 1628 de 20 de junho de 1952.

O aspecto social foi observado somente em 1982, por meio do Decreto-Lei n. 1.940, de 25 de maio de 1982, entretanto, as demandas sociais não se mostraram como o foco de operação do BNDES. Nesse sentido, vejam-se algumas palavras proferidas pelo Sr. Élvio Gaspar, diretor da Área de Inclusão Social e Crédito do BNDES em 2006, em um seminário realizado no Rio de Janeiro, em 13 de julho de 2006:

O BNDES opera em duas grandes áreas: no desenvolvimento econômico através da infra-estrutura, bens de capital e inserção internacional e também no desenvolvimento social e ambiental. Vou me ater a essa segunda parte para dizer, principalmente, que o Banco tem feito um esforço grande para ampliar sua 
ação social. No entanto, o BNDES não é substituto do Ministério da Saúde e do Ministério da Educação. Educação se faz com direito público na veia; não por empréstimos, que é o que o BNDES faz. Não é possível comparar os investimentos em saúde do Banco com os do Ministério, até porque os empréstimos são feitos para agentes privados. Por exemplo, a sociedade precisa de hospitais; esses hospitais têm que ser financiados com direito público, com investimentos orçamentários não reembolsados, com recursos distribuídos diretamente na sociedade através de um serviço público e não através de um empréstimo a um agente privado. Assim sendo, o que o BNDES faz em saúde e educação certamente será marginal em relação à necessidade da sociedade. (GASPAR, 2007, p. 19).

Para corroborar tais fatos, examina-se o relatório anual publicado no ano de 2017 , onde o BNDES informa as quantias despendidas para o setor de desenvolvimento social entre os anos de 2012 e 2016: em 2012 foram desembolsados R\$ 18,2 bilhões de reais; em 2013 foram desembolsados R \$ 21,9 bilhões de reais; em 2014 foram desembolsados R \$ 25,9 bilhões de reais; em 2015 foram desembolsados R\$ 18,6 bilhões de reais; em 2016 foram desembolsados R \$ 9,7 bilhões de reais (BANCO NACIONAL DO DESENVOLVIMENTO ECONÔMICO E SOCIAL, 2017, p. 37).

Através de um singelo comparativo, no ano de 2016, o total de desembolsos efetuados pelo Banco Público foi de $\mathrm{R} \$ 88,3$ bilhões de reais, e, como descrito anteriormente, desses números, $\mathrm{R} \$ 9,7$ bilhões de reais foram direcionados para o setor de desenvolvimento social (BANCO NACIONAL DO DESENVOLVIMENTO ECONÔMICO E SOCIAL, 2017, p. 44). Já no ano de 2015, foram desembolsados R $\$ 135,9$ bilhões de reais, sendo R $\$ 18,6$ bilhões de reais no setor de desenvolvimento social (BANCO NACIONAL DO DESENVOLVIMENTO ECONÔMICO E SOCIAL, 2016, p. 19).

Quanto aos fundamentos que justificaram a criação do BNDES, destaca-se que o caráter intervencionista traçado para o BNDES, tem suas bases ancoradas no estímulo ao desenvolvimento de setores estratégicos, além do objetivo de suprimir a carência de crédito de longo prazo presente no mercado privado, corrigindo as falhas do mercado. Os argumentos trazidos são delineados na medida em que os créditos e suportes dados pelo Banco de Desenvolvimento dão sustentação para crescimento econômico e para a promoção de direito sociais.

Alicerçado nestas premissas, veja-se que a própria existência de um banco de desenvolvimento pode ser considerada, em princípio, um mecanismo ofensivo e interventivo para a doutrina liberal, já que este seria prejudicial para o andamento das ações do mercado, inclusive em épocas de retração da atividade econômica, tendo em vista que o mercado possuiria mecanismos para efetuar a reversão de seus próprios ciclos negativos.

Além disso, a corrente doutrinária do liberalismo apresenta oposições ao excesso de atribuições discricionárias do Estado, vez que estas contribuem para o monopólio de classes escolhidas pelo governo, com amplo espaço para intervenção e controle de classes sociais com forte domínio econômico, bem como um ambiente para manipulação dos governantes em favor de suas ambições políticas. Assim, ausência de previsibilidade das ações governamentais é prejudicial 
para os interesses liberais de desenvolvimento.

$\mathrm{O}$ argumento liberal é dirigido para a visualização da credibilidade e da eficiência econômica, com eliminação das pressões advindas da presença do Estado, através da liberalização de capitais e do comércio (MELO, 2012, p. 316). Este pensamento fez uma fragmentação entre o poder político e a atividade econômica, conservando o âmbito de atuação privada contra uma interferência indevida pelo Estado (STRECK; LIMA, 2016, p. 216).

Portanto, a vertente liberal "considera que o direcionamento do crédito gera uma distorção na alocação de poupança que se reflete em elevações das taxas de juros e iniquidades no acesso ao crédito" (MAIA, 2017, p. 19-20). Ainda, "as linhas de crédito dirigido pressionam a elevação da taxa básica de juros, porque não são alocadas pela lógica do mercado - o crédito direcionado possui critérios específicos de empréstimos" (MAIA, 2017, p. 20).

Por fim, dentro de uma perspectiva liberal, a atuação do BNDES demonstraria um descompasso para com os preceitos que sustentariam esta corrente doutrinária e sua consciência de liberdade para atuação segundo seus interesses pessoais em uma economia autorregulada.

Já no que se referente ao pensamento republicano, especialmente, aquele neoateniense, relembre-se a necessidade de uma liberdade com possibilidade de escolha pelo particular sem a submissão a um poder estatal arbitrário e que não considere os aspectos de interesse público. Destarte, reivindica-se um Estado constitucional forte e consolidado, com instituições que possam formar e garantir a liberdade dos indivíduos.

As instituições que operem segundo as regras normativas estabelecidas são essenciais para a formação de uma liberdade republicana, ou seja, reconhece-se a necessidade da submissão das instituições públicas às leis, às normas positivadas, para acompanhamento e controle pela população.

Forçoso reconhecer assim que, sem a conjugação dos valores do republicanismo, haverá espaço para a predominância dos interesses privados, e, por conseguinte, as características do patrimonialismo na estrutura do Estado (LIMA, 2017, p. 120). A tradição patrimonialista incrustrada nas práticas políticas brasileiras traz uma tendência de desviar a condução das ações do Poder Público para os interesses das autoridades que praticam os atos em nome do governo. Essa é a preocupação dos liberais, para negar a necessidade de instituições estatais que sejam interventoras no mercado; e é a preocupação dos republicanos, os quais não aceitam o desvio das ações do Estado em favor do interesse particular. Há um destaque das ações voltadas para o interesse público no republicanismo, sendo estas primordiais para que sejam rejeitadas as intervenções estatais desprovidas destas finalidades.

Desse modo, se a opção política do Estado é a criação de instituições interventoras, negando desse modo, a opção liberal, cabe dar destaque às exigências republicanas, para o bom funcionamento do sistema, ressalvadas por Quentin Skinner: é indispensável a sujeição igual de todo cidadão ao domínio da lei; os fins fixados para as ações dessas instituições devem ser voltados para o interesse de toda a comunidade; não é possível admitir o exercício do poder para favorecer interesses daqueles que governam. 
Instituições públicas transparentes e o esforço participativo da população têm o condão de combater o patrimonialismo, que nos dizeres de Raymundo Faoro (1998, p. 737) representa um “aparelhamento político - uma camada social, comunitária embora nem sempre articulada, amorfa muitas vezes - impera, rege e governa, em nome próprio, num círculo impermeável de comando".

A partir destes moldes, tem-se que o BNDES possui o encargo de refrear, por exemplo, aqueles investimentos e participações acionárias que trazem benesses somente para uma parcela restrita da sociedade, e visam o controle e o comando desta classe sobre os demais setores da comunidade, tal como a estratégia das campeãs nacionais adotada em alguns governos. Pretendese impedir a permanência de interesses políticos que tenham finalidades de troca de favores com agentes econômicos e a concessão de subsídios econômicos para sociedades empresárias já consolidadas e sem a necessidade de crédito estatal para a promoção do desenvolvimento econômico ou social.

Não se pode olvidar ainda que para a liberdade republicana neorromana, importa que o Estado não atue por meio de um poder arbitrário e dominador. Assim, a interferência estatal por meio do BNDES não se constituiria como ofensiva à liberdade, quando a sua atuação esteja protegida contra as arbitrariedades de seu próprio sistema.

A utilidade do envolvimento do particular em questões públicas é outra característica que distingue a concepção de liberdade presente no liberalismo e no republicanismo neorromano. Nesse sentido, aponta-se para a necessidade de visão comunitária e de ações participativas do cidadão que tenham conhecimento sobre a importância das instituições públicas.

Neste ínterim, o enquadramento dos requisitos republicanos para com as demandas do BNDES poderia ser destacado com as seguintes características: a indispensabilidade de um planejamento que contenha as previsões, os objetivos e os procedimentos a serem tomados na condução dos investimentos, das participações acionárias, do processo de desestatização onde haja envolvimento do BNDES; a exposição pública destes procedimentos para conhecimento pela população; a demonstração de justificativas fundamentadas para com as decisões relativas aos investimentos; a presença de canais diretos para que o indivíduo possa expor suas indagações e discordâncias em relação ao plano traçado e executado pelo governo para o BNDES; a comunicação de respostas ao cidadão e a inserção de sugestões construtivas em relação ao planejamento elaborado.

Por fim, a intervenção do BNDES que nos negócios particulares é ofensiva para o liberalismo, mas não será repulsiva para os republicanos neorromanos se a referida intervenção apresentar os elementos de uma democracia contestatória, destituído do poder arbitrário e que inclui a participação política em seus procedimentos e resultados.

\subsection{O Bndes e o Confronto com a Democracia Contestatória}

Tendo em vista que o BNDES se utiliza de recursos públicos para investimentos 
ou estímulos à economia e ao desenvolvimento social, é mister que o cidadão esteja ciente do planejamento deste Banco Público, dos limites de sua atuação, e assim, possa apresentar suas opiniões e contestações naquilo que se demonstrar ofensivo ao desenvolvimento nacional.

Destarte, salientam-se os principais meios de controle técnico por outros órgãos ou poderes para com as ações do BNDES: fiscalização pelo Tribunal de Contas da União (TCU), pela Controladoria Geral da União, pelo Banco Central, pelo Poder Judiciário, pelo Ministério Público, Polícia Federal e pelo Poder Legislativo.

Cabe neste ponto, apontar para a decisão proferida em maio de 2015, onde o STF, Supremo Tribunal Federal, determinou que o BNDES apresentasse informações ao Tribunal de Contas da União - TCU sobre o empréstimo concedido ao grupo JBS/Friboi. Destaca-se a confirmação sobre o controle financeiro de recursos públicos ser indispensável em um Estado democrático de direito, bem como a transparência do destino das verbas públicas se revela primordial.

EMENTA: DIREITO ADMINISTRATIVO. CONTROLE LEGISLATIVO FINANCEIRO. CONTROLE EXTERNO. REQUISIÇÃO PELO TRIBUNAL DE CONTAS DA UNIÃO DE INFORMAÇÕES ALUSIVAS A OPERAÇÕES FINANCEIRAS REALIZADAS PELAS IMPETRANTES. RECUSA INJUSTIFICADA. DADOS NÃOACOBERTADOS PELO SIGILOBANCÁRIO E EMPRESARIAL. [...] 3. O sigilo de informações necessárias para a preservação da intimidade é relativizado quando se está diante do interesse da sociedade de se conhecer o destino dos recursos públicos. 4. Operações financeiras que envolvam recursos públicos não estão abrangidas pelo sigilo bancário a que alude a Lei Complementar $n^{\circ} 105 / 2001$, visto que as operações dessa espécie estão submetidas aos princípios da administração pública insculpidos no art. 37 da Constituição Federal. Em tais situações, é prerrogativa constitucional do Tribunal [TCU] o acesso a informações relacionadas a operações financiadas com recursos públicos. 5. O segredo como "alma do negócio" consubstancia a máxima cotidiana inaplicável em casos análogos ao sub judice, tanto mais que, quem contrata com o poder público não pode ter segredos, especialmente se a revelação for necessária para o controle da legitimidade do emprego dos recursos públicos. É que a contratação pública não pode ser feita em esconderijos envernizados por um arcabouço jurídico capaz de impedir o controle social quanto ao emprego das verbas públicas. [...]. (BRASIL, 2015).

Veja-se que neste acórdão, restou corroborado que o controle financeiro de recursos públicos é substancial em um Estado democrático de direito, bem como a transparência do destino das verbas públicas se revela fundamental inclusive para o controle por órgãos externos como o TCU.

Ademais, note-se que, conforme as administrações designadas para o banco estatal, bem como os governantes eleitos para cada época, o modelo de gestão do BNDES foi modificado para acompanhar os modelos de desenvolvimento do governo o qual estavam vinculados. Verifica-se um comportamento que sucumbe às necessidades governamentais imediatas e às necessidades eleitorais, mostrando a ausência de um planejamento estatal mais duradouro com e estudos 
continuados para as ações do BNDES.

Outrossim, relembre-se a estratégia de investimentos das campeãs nacionais adotada principalmente a partir de 2008 pelo BNDES. Nesta época, esta instituição direcionou seus esforços de auxílio e investimentos para algumas empresas e para determinados setores da economia, objetivando a consolidação destas nas cadeias globais de produção (ALMEIDA; LIMA-DEOLIVEIRA; SCHNEIDER, 2014, p. 16). Contudo, a referida estratégia não encontrou qualquer referência em documentos oficiais que informam sobre a política de governo, não obstante a defesa do BNDES que esta se trata de uma política industrial do país (ALMEIDA; LIMA-DEOLIVEIRA; SCHNEIDER, 2014, p. 16).

Convém ponderar que a composição destas campeãs nacionais também apresenta problemas, senão vejamos:

Ela é concentrada em nove grandes empresas - Vale, Petrobras, Eletrobras, Fibria, Suzano, JBS, Copel, CPFL Energia, AES Tietê - que representam $83 \%$ do valor total. São companhias com ações listadas em bolsas de valores no Brasil e EUA e que definitivamente prescindem de recursos da sociedade para se financiarem. Trata-se novamente de sério problema de má alocação. (BRANCO, 2017, p. 5).

Veja-se que este artifício de formação de empresas líderes ainda proporciona custos para os fornecedores no início da cadeia, já que são submetidos a um mercado concentrado, com um número limitado de compradores, cujos efeitos são sentidos especialmente pelas micro e pequenas empresas (ALMEIDA, 2009, p. 34). Aliás, "ao eleger vencedores, a abordagem pró-negócios também elege os perdedores, que são, evidentemente, os empresários e trabalhadores da grande maioria das empresas, que não foram eleitas para serem as campeãs" (AMADEO, FRAGA, 2012).

Pode-se constatar a consolidação da concentração de renda entre estas sociedades empresárias, e, consequentemente, a elevação dos níveis de desigualdade econômicas e sociais no país. A estabilidade destas empresas de grande porte e sua de facilidade de acesso aos mercados financeiros, são elementos que deveriam sugerir o afastamento do BNDES em suas finanças, vez que estas sociedades empresárias procuram somente reduzir o custo de seus projetos através da intervenção estatal.

Este modelo baseado nas campeãs nacionais ainda causa uma estagnação na estrutura produtiva, já que não direciona investimentos para novas soluções e novos ramos empresariais. A falta de diversificação dos aportes estatais ou participações acionárias pelo BNDES, aumenta a concentração do mercado e paralisa um processo de novas oportunidades econômicas.

Questiona-se ainda: quais foram os interesses públicos envolvidos nas concessões de financiamos ou participações acionárias nos contratos firmados, por exemplo, com o grupo JBS? Quais os objetivos destinados ao desenvolvimento nacional estipuladas nestes acordos? Estes questionamentos surgem diante das dúvidas acerca do caráter impessoal das decisões do BNDES e também das incertezas quanto à motivação na concessão de crédito e suas relações com os interesses privados de uma determinada classe produtiva. 
É de pontuar ainda que o direcionamento do crédito através de preferências governamentais tem o condão de afetar diretamente os mais diversos setores da economia. A título exemplificativo, a opção pela concessão de crédito subsidiado a determinada indústria metalúrgica, fará com que esta empresa tenha vantagens competitivas ao oferecer seu produto ao mercado e, já que esta empresa foi beneficiada com um financiamento com juros reduzidos, terá condições de repassar seu produto com valores mais baixos que o seu concorrente.

Destaca-se também que a noção de transparência do BNDES tem se direcionado com mais ênfase para a proteção e estabilidade do Sistema Financeiro Nacional - SFN, ou para a proteção do sigilo bancário do particular contratante, ignorando a necessidade de informações para o cidadão, essenciais para a efetivação do controle social.

Portanto, deve-se buscar o aperfeiçoamento do BNDES a partir da apuração de seus vícios (SOARES, 2003, p. 13), formando-se uma visão crítica sobre o alcance das finalidades voltadas para o interesse público, e assim, "a vinculação de um novo modelo de desenvolvimento econômico a um novo contrato social levanta a questão dos valores cívicos e de como os interesses individuais podem participar da consolidação dos preceitos públicos" (RUEDIGER; RICCIO, 2005, p. 31).

Dentro de uma visão republicana, é possível discorrer sobre a inevitabilidade de um planejamento estatal no BNDES voltado para a transparência nas informações, controle pelo particular das ações públicas para possibilitar o diálogo público. Entretanto, dentro daqueles canais disponibilizados pelo BNDES, não se observa, algum mecanismo que permita a influência da sociedade civil nos destinos sobre investimentos ou subscrições acionárias. Não há qualquer exposição, seja em sites, circulares ou outros veículos, sobre o planejamento elaborado e os fundamentos para determinada decisão de alocação de recursos públicos.

Não obstante algumas alterações no comportamento do BNDES ao longo dos anos, os dados que se apresentam visíveis, não se mostram razoáveis para observação e analise de um planejamento voltado para interesse público pelo cidadão, características que são imperativas para a formação de uma democracia contestatória. A ausência de demonstração do planejamento e da motivação para promoção do desenvolvimento nacional se mostram visíveis no cenário público que envolve o BNDES, merecendo urgente reparo e adequações.

\section{CONCLUSÃO}

A partir dos ideais do liberalismo, a valorização dos ideais individuais foi estampada de forma tão expressiva durante as décadas, que a concepção de participação na vida pública se tornou distante e sem evidenciação na sociedade. Assim, o republicanismo se reapresentou nas discussões doutrinárias para indicar outro horizonte e que não seja restrito aos moldes projetados pelo liberalismo.

Diante do estudo realizado, viu-se que os particulares devem ser livres da dominação para que possam usufruir de sua liberdade negativa elencada no republicanismo neorromano. Os 
cidadãos devem ser livres de atos de interferência estatais e de indivíduos que sejam cometidos de forma arbitrária, ou seja, os cidadãos devem viver sem estar ao arbítrio da decisão de outros ilimitadamente. Conforme anotado, é indispensável a sujeição igual de todo cidadão ao domínio da lei; os fins fixados para as ações das instituições do Estado devem ser voltados para o interesse de toda a comunidade; não é possível admitir o exercício do poder para favorecer interesses daqueles que governam.

O republicanismo, em especial a vertente neorromana, denota um ponto de vista diferenciado e que rejeita uma única intenção de buscar somente as vontades individuais e ignorar os desejos comuns, mas respeita a complexidade das sociedades atuais ao não exigir uma participação integral e direta dos cidadãos na vida pública.

Destarte, viu-se que a formação de uma democracia contestatória exige a presença de decisões que favoreçam o interesse público e também abrange características que procuram impedir o exercício de arbitrariedades pelo Estado e pelos particulares.

Por conseguinte, o BNDES, como uma das principais instituições estatais brasileiras, deve pautar suas ações em um maior vínculo democrático com a sociedade, disponibilizando técnicas para avaliar os fundamentos de suas decisões.

Como dito, as práticas realizadas dentro deste Banco Público possuem uma vertente econômica de grande destaque, de forma que suas as decisões são originárias de governantes e suas estratégias políticas, afetando diretamente o nível e o tipo de liberdade que os cidadãos usufruirão. Exatamente por tais fatos, importa que haja uma correlação entre as providências e as deliberações desta instituição com o interesse público, e consequentemente com as opiniões e análises dos cidadãos para o exame de seu desempenho.

Ressalte-se que o planejamento estatal possui um ponto de intensa relevância quando se trata do BNDES. Há uma urgente necessidade de planejamento e da elaboração de parâmetros e métodos que conduzirão ao desenvolvimento almejado.

A sociedade civil, como sendo uma das mais relevantes fontes de recursos para os desembolsos do BNDES, deve ser comunicada sobre os intentos do Banco e sobre os retornos almejados com os investimentos e sobre as respostas e os retornos para a população.

Por fim, ainda se observam carências e lacunas no relacionamento entre o Banco Estatal e o cidadão, merecendo ser reavaliadas e reformuladas, de forma que este indivíduo não pode estar subjugado a decisões arbitrárias.

\section{REFERÊNCIAS}

ALMEIDA, Mansueto. Desafios da real política industrial brasileira do século XXI. Brasília: Ipea, 2009. (Texto para Discussão, n. 1452). Disponível em: http://www.ipea.gov.br/portal/ index.php?option $=$ com_content\&view $=$ article $\&$ id $=4988 \% 3$ Atd-1452-desafios-da-real-politicaindustrial-brasileira-do-seculo-xxi\&catid $=272 \% 3$ A2009\&directory $=1 \&$ Itemid=1. Acesso em: 13 jan. 2018. 
ALMEIDA, Mansueto; LIMA-DE-OLIVEIRA, Renato; SCHNEIDER, Ben Ross. Política industrial e empresas estatais no Brasil: BNDES e Petrobras. Brasília: Ipea, 2014. (Texto para Discussão, n. 2013). Disponível em: https://www.econstor.eu/ bitstream/10419/121585/1/814789773.pdf. Acesso em: 13 jan. 2018.

AMADEO, Edward; FRAGA, Arminio. O fim da herança bendita? O Estado de São Paulo, São Paulo, 16 dez. 2012. Disponível em: http://opiniao.estadao.com.br/noticias/geral,o-fim-daheranca-bendita-imp-,974177. Acesso em: 13 jan. 2018.

BANCO NACIONAL DO DESENVOLVIMENTO ECONÔMICO E SOCIAL. Relatório anual BNDES, 2015. Rio de Janeiro: Banco Nacional de Desenvolvimento Econômico e Social, 2016.

BANCO NACIONAL DO DESENVOLVIMENTO ECONÔMICO E SOCIAL. Relatório anual BNDES, 2016. Rio de Janeiro: Banco Nacional de Desenvolvimento Econômico e Social, 2017.

BERCOVICI, Gilberto. Constituição econômica e desenvolvimento: uma leitura a partir da Constituição de 1988. São Paulo: Malheiros Editores, 2005.

BERCOVICI, Gilberto. Desigualdades regionais, Estado e Constituição. São Paulo: Max Limonad, 2003.

BERLIN, Isaiah. Dois conceitos de liberdade. In: BERLIN, Isaiah. Estudos sobre a humanidade: uma antologia de ensaios. Tradução de Rosaura Eichenberg. São Paulo: Companhia das Letras, 2002.

BRANCO, Roberto Castello. Qual o papel do BNDES? Revista RI: relação com investidores, Rio de Janeiro, n. 214, ago. 2017. Disponível em: http://www.acionista.com.br/mercado/artigos mercado/210917-revista-ri-qual-o-papel-do-bndes.pdf. Acesso em: 13 jan. 2018.

BRASIL. [Constituição (1988)]. Constituição da República Federativa do Brasil de 1988. Brasília, DF: Presidência da República, 1988. Disponível em: http://www.planalto.gov.br/ ccivil_03/constituicao/constituicaocompilado.htm. Acesso em: 7 set. 2017.

BRASIL. Supremo Tribunal Federal. Acórdão no Mandado de Segurança n. 33.340-DF. Relator: FUX, Luiz. Julgado em 26 de maio de 2015. Primeira Turma. Disponível em: http:// redir.stf.jus.br/paginadorpub/paginador.jsp?docTP=TP\&docID=8978494. Acesso em: 29 dez. 2016.

CONSTANT, Benjamin. Da liberdade dos antigos comparada à dos modernos. In: FILOSOFIA política 2. Porto Alegre: L\&PM Editores, 1985.

ELIAS, Maria Lígia Ganacim Granado Rodrigues. Democracia e participação política no novo republicanismo: um estudo sobre o pensamento de Philip Pettit. 2008. Dissertação (Mestrado em Sociologia Política) - Universidade Federal de Santa Catarina, Florianópolis, 2008.

FAORO, Raymundo. Os donos do poder: formação do patronato político brasileiro. 13. ed. São Paulo: Globo, 1998. v. 2.

FERRAZ FILHO, José Francisco Cunha. Arts. $1^{\circ}$ ao $5^{\circ}$. In: MACHADO, Costa (org.).

Constituição Federal interpretada: artigo por artigo, parágrafo por parágrafo. 3. ed. São Paulo: Manole, 2012. 
GASPAR, Élvio. O BNDES que temos e o BNDES que queremos. In: FURTADO, Fabrina Pontes (org.). O BNDES que temos e o que queremos: o papel do BNDES no financiamento do desenvolvimento nacional democrático. São Paulo: Expressão Popular, 2007.

HOBBES, Thomas. Leviatã: ou a matéria, forma e poder de um Estado eclesiástico e civil. Tradução de Rosina D’Angina. São Paulo: Martin Claret, 2009.

JAGUARIBE, Helio. Estudos filosóficos e políticos. Brasília: Funag, 2013.

LAFER, Celso. Ensaios sobre a liberdade. São Paulo: Editora Perspectiva, 1980.

LIMA, Raimundo Márcio Ribeiro. Republicanismo, federalismo e patrimonialismo: a formação das instituições políticas brasileiras como um mosaico de contradições. Fides: revista de filosofia do direito, do estado e da sociedade, Natal, v. 8, n. 1, p. 114-132, jan./jun. 2017. Disponível em: http://www.revistafides.com/ojs/index.php/br/article/view/574/925. Acesso em: 14 jan. 2017.

LOVETT, Frank; PETTIT, Philip. Neorepublicanism: a normative and institutional research program. Annual Review Political Science, Palo Alto, v. 12, p. 11-29, 2009. Disponível em: https://www.princeton.edu/ ppettit/papers/2009/Neorepublicanism_\%20A\%20Normative $\% 20$ and\%20Institutional\%20Research\%20Program\%20-\%20Annual\%20Review\%20of\%20 Political\%20Science,\%2012(1)_11\%20-\%20Full\%20Text.pdf. Acesso em: 10 out. 2017.

MAIA, Bento Antunes de Andrade. O papel do BNDES: críticas ao crédito e ao FAT. Disponível em: http://www.planejamento.gov.br/secretarias/upload/Arquivos/dest/premio_dest/mencao_ honrosa_custo_premio_dest_2008.pdf. Acesso em: 7 nov. 2017.

MEDINA, Javier García. Tres perspectivas republicanas sobre la relación entre libertad, derechos y ley: Rousseau, Kant y Pettit. Derechos y Libertades: revista de filosofía del derecho y derechos humanos, Madrid, n. 16, p. 101-135, 2007.

MELO, Vico Dênis Sousa. Reformas liberais e descentralização no Brasil (1990-2002): a atuação do Banco Nacional de Desenvolvimento Econômico e Social (BNDES). Anos 90. Revista do Programa de Pós-Graduação em História da Universidade Federal do Rio Grande do Sul, Porto Alegre, v. 19, n. 36, p. 315-337, dez. 2012. Disponível em: http://www.seer.ufrgs.br/index. php/anos90/article/view/27464/25782. Acesso em: 7 nov. 2017.

PETTIT, Philip. Republicanismo: una teoria sobre la libertad y el gobierno. Barcelona: Ediciones Paidós Ibérica, 1999.

PETTIT, Philip. Teoria da liberdade. Tradução de Renato Sérgio Pubo Maciel. Belo Horizonte: Del Rey, 2007.

PINTO, Ricardo Leite. Uma introdução ao neo-republicanismo. Revista Análise Social, Lisboa, v. 36, n. 158-159, p. 461-485, 2001.

RAMOS, César Augusto. A concepção republicana de liberdade como não-dominação. Crítica: revista de filosofia, Londrina, v. 12, n. 36, p. 301-336, out. 2007.

RAMOS, César Augusto. O liberalismo político e seus críticos. Crítica: revista de filosofia, Londrina, v. 10, n. 32, p. 229-264, out. 2005. 
REALE, Miguel. Filosofia do direito. 20. ed. São Paulo: Saraiva, 2002.

RUEDIGER, Marco Aurélio; RICCIO, Vicente. O novo contrato social: desenvolvimento e justiça em uma sociedade completa. In: CALVACANTI, Bianor Scelza; RUEDIGER, Marco Aurélio; SOBREIRA, Rogério (org.). Desenvolvimento e construção nacional: políticas públicas. Rio de Janeiro: Editora FGV, 2005.

SEN, Amartya. Desenvolvimento como liberdade. Tradução de Laura Teixeira Motta. São Paulo: Companhia das Letras, 2000.

SILVA, Ricardo. Republicanismo neo-romano e democracia contestatória. Revista de Sociologia e Política, Curitiba, v. 19, n. 39, p. 35-51, jun. 2011. Disponível em: http:/www.scielo.br/scielo. php?script=sci_arttext\&pid=S0104-44782011000200004\&lng=en\&nrm=iso. Acesso em: 9 out. 2017.

SKINNER, Quentin. A liberdade antes do liberalismo. Tradução de Raul Fiker. São Paulo: Editora UNESP, 1999.

SOARES, Marcos Antônio Striquer. Características do presidencialismo no Brasil e fragilidade democrática: dificuldades de controle do presidente da República no Brasil. Revista Semina: ciências sociais e humanas, Londrina, v. 24, p. 1-24, set. 2003. Disponível em: http://www.uel.br/ revistas/uel/index.php/seminasoc/article/view/3832/3078. Acesso em: 22 nov. 2017.

STRECK, Lenio Luiz; LIMA, Danilo Pereira. Liberalismo à moda brasileira: o velho problema do capitalismo politicamente orientado. Revista Opinião Jurídica, Fortaleza, ano 14, n. 18, p. 207-228, jan./jun. 2016.

Como citar: MALAQUE, Déborah de Meira; STRIQUER SOARES, Marcos Antônio. O BNDES nas visões de liberalismo e do republicanismo neorromano de Philip Pettit. Revista do Direito Público, Londrina, v. 15, n. 1, p. 26-45, abr. 2020. DOI: 10.5433/24157-108104-1.2020v15n1 p. 26. ISSN: 1980-511X

Recebido em: 29/08/2018

Aprovado em: 13/01/2020 